Article

\title{
Peat Fibers and Finely Ground Peat Powder for Application in Asphalt
}

\author{
Patricia Kara De Maeijer ${ }^{1, *(\mathbb{C})}$, Hilde Soenen $\left.{ }^{2}{ }^{(}\right)$, Wim Van den bergh ${ }^{1}{ }^{(D}$, Johan Blom ${ }^{1}{ }^{(}$, \\ Geert Jacobs ${ }^{1}\left[\right.$ and Jan Stoop ${ }^{1}$ (I)
}

1 EMIB Research Group, Faculty of Applied Engineering, University of Antwerp, 2020 Antwerp, Belgium; wim.vandenbergh@uantwerpen.be (W.V.d.b.); johan.blom@uantwerpen.be (J.B.); geert.jacobs@uantwerpen.be (G.J.); jan.stoop@uantwerpen.be (J.S.)

2 Nynas NV, Bitumen Research, 2020 Antwerp, Belgium; hilde.soenen@nynas.com

* Correspondence: patricija.karademaeijer@uantwerpen.be; Tel.: +32-3-265-8851

Received: 20 November 2018; Accepted: 28 December 2018; Published: 4 January 2019

check for updates

\begin{abstract}
In this study, the feasibility of a natural peat fiber and finely ground peat powder as a modifier for bitumen was investigated. Initially, the as-received peat material was characterized in detail: the material was ground to various degrees, separated into fiber and powder fractions, and the gradation of the powder fraction as well as the size of the fibers were determined. A possible solubility in bitumen, the moisture content, and the density of both fractions were evaluated, and a limited chemical characterization of the fibers was conducted. Secondly, the rheological behavior of the powder and the fibers when blended with bitumen was evaluated. Additionally, a limited asphalt study was conducted. The rheological data showed the stiffening effects of the powder fraction and the presence of a fiber network, which were obvious as a plateau modulus towards lower frequencies. The fiber network was strain-dependent and showed elastic effects. This was further confirmed by the multiple stress creep recovery (MSCRT) tests. These tests also indicated that the fibers should improve the rutting resistance, although it was not possible to confirm this in asphalt rutting tests. Asphalt drainage tests demonstrated that adding dry peat, whether this is ground or not, is effective in reducing the binder drainage. However, the data also revealed that the amount of added peat fibers and powder should be limited to avoid difficulties in the compaction of these asphalt mixes.
\end{abstract}

Keywords: peat; asphalt; rheology; drainage; wet process; rutting

\section{Introduction}

Peat is an accumulation of partially decayed vegetation or organic matter formed in wetlands: fens with typical plants, such as bushes and trees, which are fed by ground water rich in nutrients; and bogs with typical plants, such as mosses, cotton grass, and heather, which are fed by rain water poor in nutrients [1]. The most-used material is Sphagnum moss peat, which is the main material building up in bogs in the Northern hemisphere. In some countries, peat is regarded as a slow-renewable material, although the rate of extraction and usage of peat far exceeds the rate of reforming. In Finland in 2016, bogland usage was 9.39 million ha with peat usage of 3 million $\mathrm{m}^{3}$ and $3 \%$ of the annual energy production was provided by peat [2]. Peat, apart from usage as an energy provider, has agricultural applications, such as increasing the water-holding capacity of sands, and industrial applications, such as an oil absorbent or as an efficient filtration medium for mine waste streams, municipal storm drainage, and septic systems [3].

The major distresses that occur in asphalt pavement are related to crack formation, permanent deformation, and water damage. Moreover, the properties of asphalt change with time, mainly due to ageing effects occurring in the binder phase. Additives, such as polymers, crumb rubber, waxes, 
and surface-active components, have been used to prevent distresses and improve the durability of the pavement. Among the additives, fibers have also been used. Fibers, in particular cellulose fibers, are added to avoid binder drainage during transportation from the asphalt plant to the construction site, typically in open mixes that contain a high binder percentage. Fibers have also been added for other reasons, such as increasing the viscosity, and, related to this, the rutting resistance. Glass fibers, for example, have a potential to improve fatigue life and deformation characteristics by increasing the rutting resistance [4]. The application of natural fibers, such as banana [5], bamboo [6], cellulose [7], coconut [8,9], hemp [10], jute [11], kapok [12], peat [13,14] and sisal [15], has so far been used for improving the drainage, water sensitivity, and stability, and increasing the tensile strength, of the asphalt pavement. Typically, the optimum added fiber content into the asphalt mix is $0.3-0.5 \%$ by weight of the asphalt mix [16]. In terms of workability, mixes with fibers showed a slight increase in the optimum binder content compared to the control mix. This is comparable to the addition of very fine aggregates. The proper quantity of bitumen to coat the fibers is dependent on the absorption and the surface area of the fibers. Therefore, this content is affected not only by the fiber concentration but also by the fiber type [17]. In addition, the degree of homogeneity or dispersion of the fibers within the mix is also important and determines the strength of the resulting mixes [4]. If the fibers are longer, typically more than $40 \mathrm{~mm}$, a so called "balling" problem may occur, i.e., some of the fibers may lump together, and other fibers may not blend well with bitumen. Short fibers may not provide any reinforcement effect and can serve just as a filler in the mix [17]. The inclusion of fibers during the mixing process as a stabilizing agent has several advantages, including the possibility of using an increased binder content, creating an increased film thickness around the aggregate, an increased mix stability, and interlocking between the fibers and the aggregates, which improves the strength and reduces the possibility of drain down during transport and paving. Peat has already been applied in asphalt as a stabilizing additive for peat-based asphalt-concrete mixes, providing high performance to the road surface at a low cost [13].

Peat has perhaps a unique trait. Wettability, or the hydrophilic property of the peat, is observed as long as the peat contains a minimum moisture level (depending on the peat type, this is around $70 \%$ ). Below this level, the hydrophilic character of peat weakens, and it becomes hydrophobic, meaning it will expel water [18]. For the application of fibers in bitumen or asphalt, hydrophobic characteristics are preferred.

This study will discuss the results of an investigation on peat itself and on the effects of adding peat powder and peat fibers into bituminous binders and the asphalt mix, where peat is seen as an example of a natural additive, such as cellulose and many other fiber types.

\section{Materials and Methods}

\subsection{Materials}

The Finnish company VAPO Fibers provided different sizes of peat material: medium (PM), long (PL), and extra-long (PEL) peat fibers with approximate lengths of $<8 \mathrm{~mm},<16 \mathrm{~mm}$, and $>16$ $\mathrm{mm}$, respectively. Extra-long peat fibers (PEL) with a moisture content of $20 \mathrm{wt} \%$ and $55 \mathrm{wt} \%$ were chosen for the present study, and denoted as PEL20 and PEL55, respectively. Peat was dried for at least $2 \mathrm{~h}$ in an oven at $110^{\circ} \mathrm{C}$ before applying it in the experiments. Peat was ground in a blender "Philips ProBlend 6", which resulted in a fine powder mixed with a fiber fraction $(10-30 \mathrm{~mm})$. Ground peat was subsequently sieved to separate the fiber from the powder fraction (see Figure 1a,b).

Three different powders: PEL20, PEL20(3), and fine FPEL20, with a grinding time of 1, 3, and 10 minutes, respectively, were obtained (see Figure 2a). The granulometric composition of these three powders in comparison to Duras II filler is shown in Figure 2b. It can be seen in Figure 3a that powders after grinding for $3 \mathrm{~min}$ still may contain very fine fiber fractions (below $1 \mathrm{~mm}$ ). Grinding for a longer time excluded this possibility. During the sieving of peat and the separation of fibers and 
powder, it was observed that in the as-received peat the fiber content is around $3 \%$, and the powder content around $97 \%$.

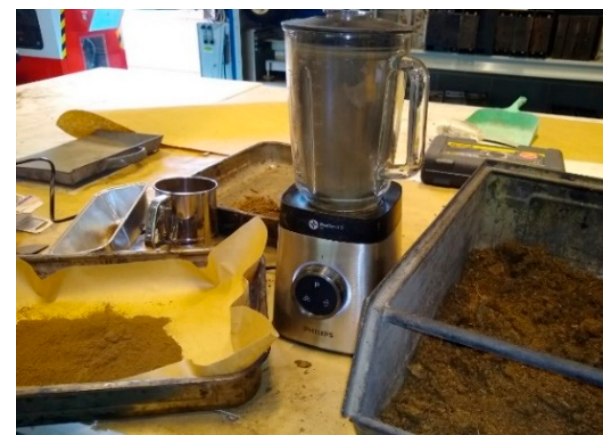

(a)

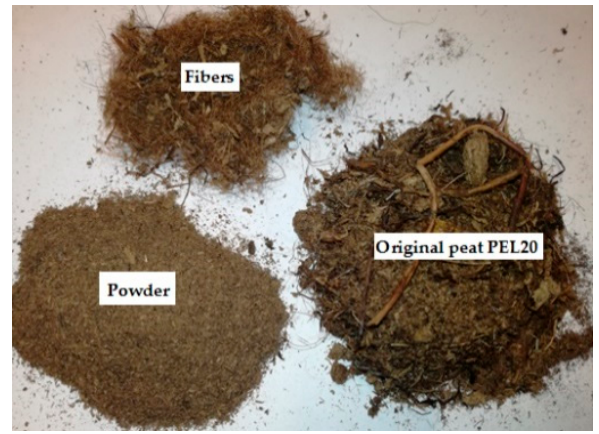

(b)

Figure 1. The preparation of peat material for testing: (a) grinding and (b) sieving.

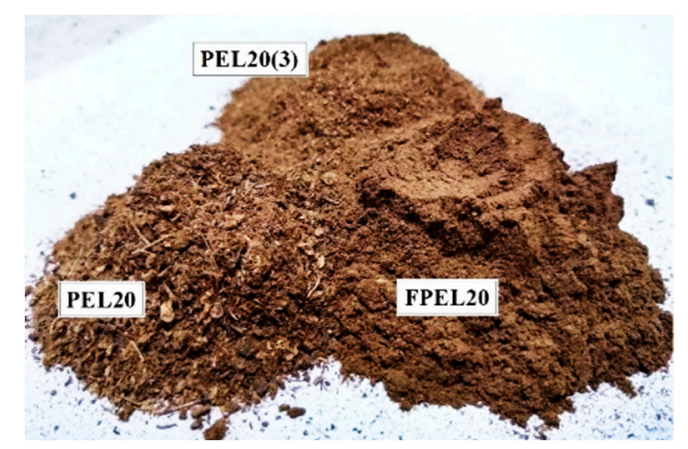

(a)

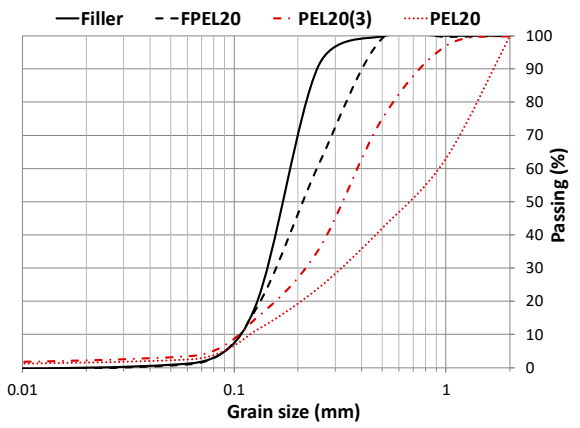

(b)

Figure 2. (a) The obtained peat powders and (b) the granulometric composition of the peat powders and filler.

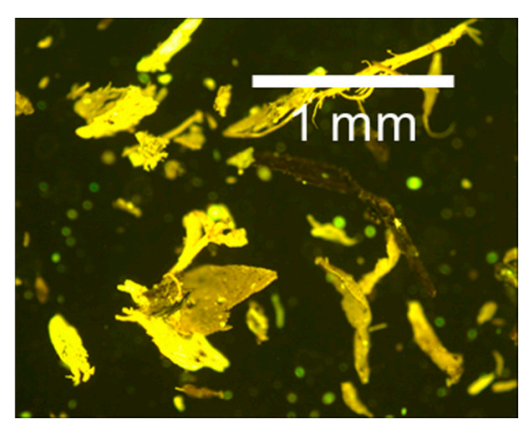

(a)

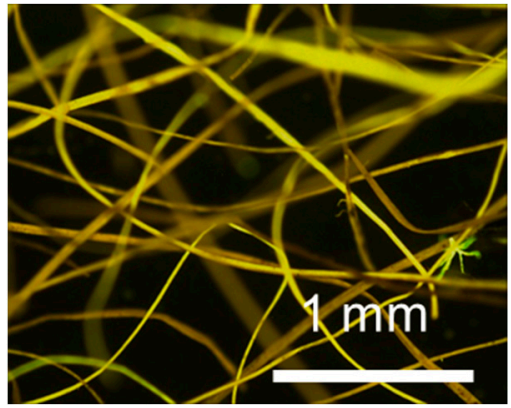

(b)

Figure 3. An example of fluorescence images of PEL20: (a) powder and (b) fibers (scale 50×).

The base bitumen was a standard 70/100 unmodified binder, with a penetration of $70 \mathrm{dmm}$ and a softening point of $47.2^{\circ} \mathrm{C}$.

\subsection{Test Methods}

The density of peat fibers and powders was defined according to the standard NBN EN 15326+A1 [19]. In this paper, toluene was used as the test liquid.

Fourier Transform Infrared Spectroscopy (FT-IR) combined with attenuated total reflection (ATR) was used. The instrument was a Nicolet IS 1, with a diamond cell (smart-orbit). 
Fluorescence microscopy was performed with a Carl Zeiss Axioskop 40Fl microscope equipped with a digital camera DeltaPix DP200. In fluorescence mode, a high-pressure mercury arc lamp HBO50, which transmits intense light with a wavelength between 450 and $490 \mathrm{~nm}$, was used. Microscopy images of peat powder FPEL20 and fibers are shown in Figure 3a,b. These images give an indication of the variation in the particle and fiber shape and size.

Scanning Electron Microscopy (SEM) images were scanned using a Coxem EM 30 P. A high vacuum and Tungsten element with an accelerating voltage of $20 \mathrm{KV}$ and a magnification of 236 times were used. In Figure 4, a SEM image of the fiber fraction is shown, indicating the thickness and thickness variability within this fraction, and a minor porosity effect on the fibers.

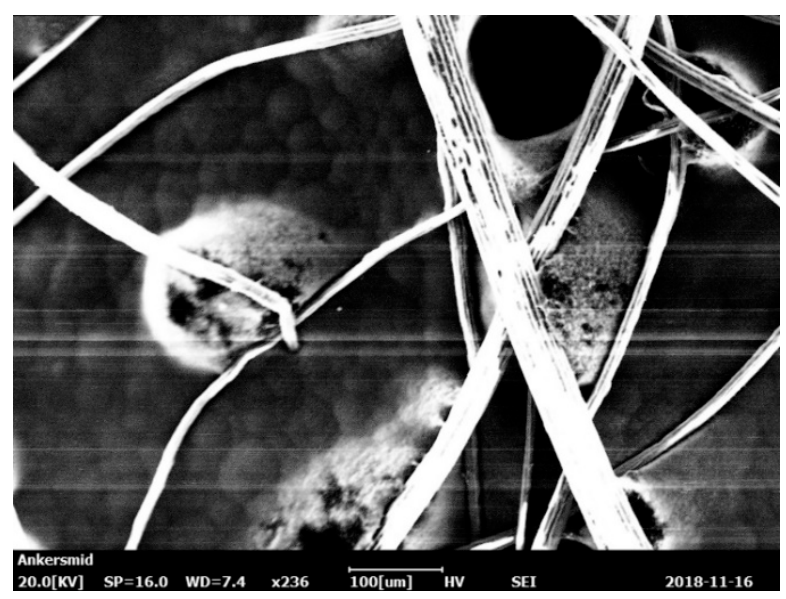

Figure 4. An SEM image of peat fibers (scale 236×) with a fiber thickness of $50 \mu \mathrm{m}$ (the appearance of bubbles in the background is the result of evaporation of the glue on the heated surface).

The rheological properties were determined by an Anton Paar MCR 500 rheometer. Measurements were conducted at $50{ }^{\circ} \mathrm{C}$ using the $25 \mathrm{~mm}$ plate geometry to relate with the rutting test. The base binder was investigated at a gap setting of $1 \mathrm{~mm}$, while samples modified with peat were investigated with a gap setting of $1.5 \mathrm{~mm}$. Stress sweeps, frequency sweeps, and repeated creep measurements were performed. For some samples, frequency sweeps were also recorded at $40{ }^{\circ} \mathrm{C}, 60^{\circ} \mathrm{C}$, and $70{ }^{\circ} \mathrm{C}$ to observe the effect of temperature. The specimens were prepared in silicon moulds and afterwards transferred to the rheometer plate. Special precautions to obtain repeatable results were taken, which will be discussed in the results section.

The binder drainage test was performed in accordance with NBN EN 12697-18 [20] using drainage baskets constructed from $3.15 \mathrm{~mm}$ perforated stainless-steel sheets, in accordance with ISO 3310-2, on the side and base, to form 100-mm cubes with feet at each corner of the base. The asphalt mixes consisted of $1100 \mathrm{~g}$ batches of (loose) stone mastic asphalt (SMA) mix with the following composition: $70.7 \%$ crushed porphyry aggregates with the maximum size of $10 \mathrm{~mm}, 20.4 \%$ crushed porphyry sand, $8.90 \%$ Duras II filler, and $6.9 \%$ bitumen of standard penetration grade $70 / 100$.

The rutting resistance of asphalt mixes was evaluated using the wheel tracking test in accordance with standard NBN EN 12697-22 [21]. The same mix composition as for the drainage tests was used for all of the measurements. Six slabs (see Figure 5a) with dimensions $18 \times 50 \times 5 \mathrm{~cm}$ were produced. The asphalt mixing temperature was $150{ }^{\circ} \mathrm{C}$.

Wheel tracking tests were performed with the LCP rut tester at $50{ }^{\circ} \mathrm{C}$. The slabs were conditioned at $50{ }^{\circ} \mathrm{C}$ for a period of $12 \mathrm{~h}$ prior to the testing. The rut depth in the slabs was measured manually, using a specifically designed setup (see Figure $5 b$ ) at 15 predetermined locations. Rut depths were measured after 1 000, 3 000, 5 000, 10 000, 20 000, and 30000 load cycles.

The volumetric properties of the asphalt slabs were determined according to NBN EN 12697 [22,23]. 


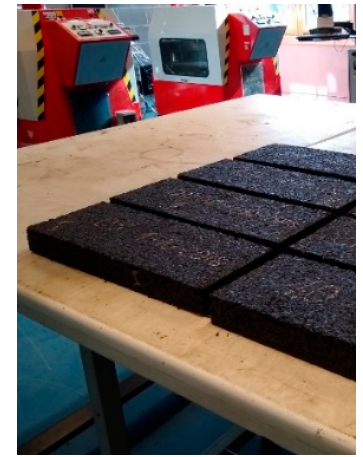

(a)

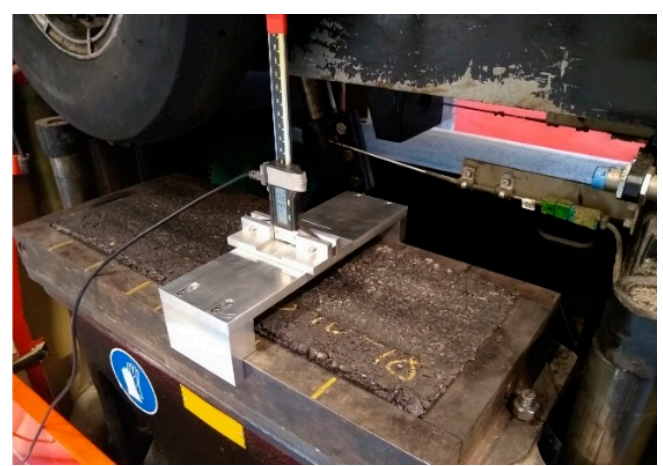

(b)

Figure 5. The rutting test: (a) the prepared slabs for testing and (b) the rut depth measuring procedure.

\section{Results and Discussion}

Before using the peat material in bitumen or asphalt, several simple tests were carried out to investigate whether the peat is blending or interacting with, or possibly even modifying, the bitumen, and which properties it may influence. To have an indication of the solubility of the peat or peat fractions in bitumen, the solubility in several organic solvents, such as toluene $\left(\rho=870 \mathrm{~kg} / \mathrm{m}^{3}\right)$, acetone $\left(\rho=781 \mathrm{~kg} / \mathrm{m}^{3}\right)$, and heptane $\left(\rho=684 \mathrm{~kg} / \mathrm{m}^{3}\right)$, was investigated (see Figure 6). It was concluded that there is no solubility in any of these solvents, and therefore no solubility in bitumen is expected. However, for the fine peat powder FPEL20, it was observed that the solution was slightly colored in toluene and acetone (see Figure 6a, the photograph was taken after $24 \mathrm{~h}$ ). That indicates that a minor solubility of this powder FPEL20 may occur in bitumen. The solubility tests also demonstrate that the density of the peat fibers and powder is between 1 and $0.87 \mathrm{~kg} / \mathrm{m}^{3}$. A more exact determination, according to NBN EN 15326+A1, showed that the average density for the powders varied from $929 \mathrm{~kg} / \mathrm{m}^{3}$ to $989 \mathrm{~kg} / \mathrm{m}^{3}$, and for the fibers it was $989 \mathrm{~kg} / \mathrm{m}^{3}$.

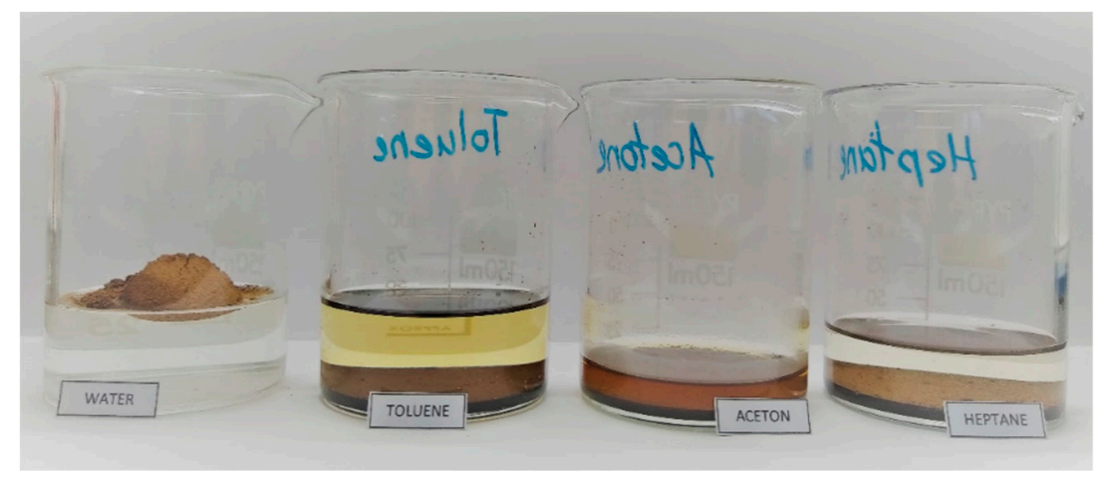

(a)

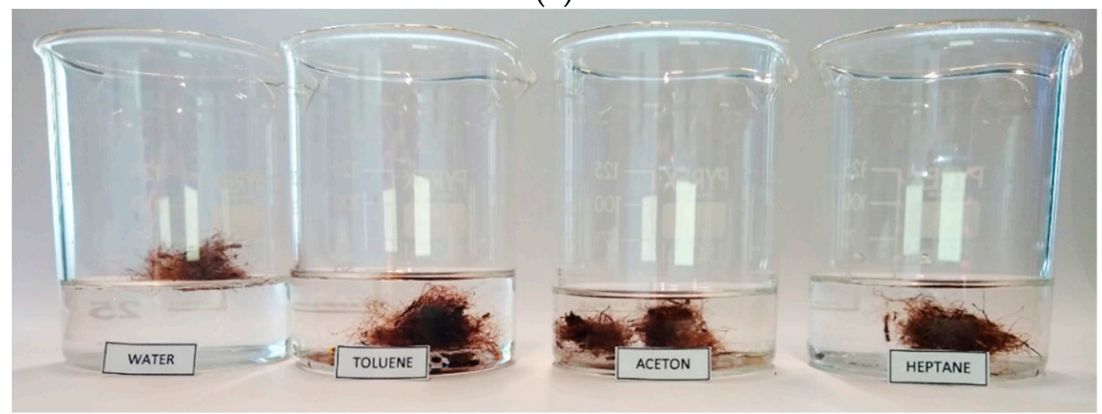

(b)

Figure 6. The solubility test of peat (a) powder and (b) fibers. 
Natural materials often contain moisture, and when blending such materials in asphalt it is important to remove this moisture or at least to know the percentage of moisture. According to the literature, three types of water could be present in peat: chemically bound, capillary, and free water. The chemically bound water is usually the most difficult to remove. Regarding the moisture content of peat, when heating an initial mix of peat fibers and powder, a quick decrease in weight was observed, probably due to the free water fraction, which could be very easily removed. This stage is followed by a much slower weight decrease, which is probably related to capillary water, which is more difficult to remove. It can be noted that, after drying, the peat mix weight is again increasing, indicating that the material reabsorbs moisture again from the environment. Therefore, peat powder and fibers were kept in a dry atmosphere after drying and before applying them in bitumen or asphalt tests (see Figure 7).

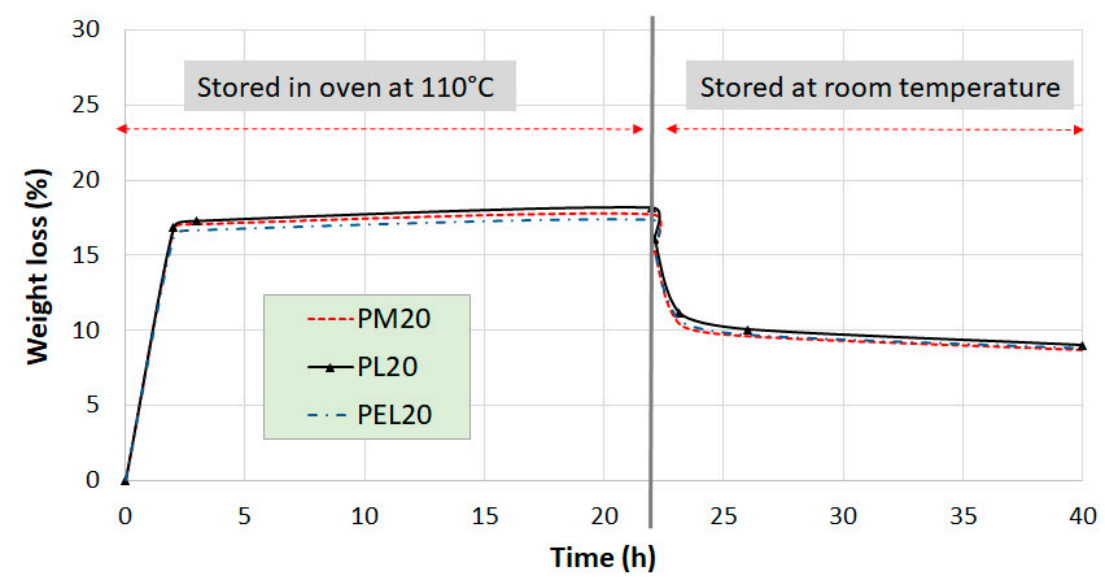

Figure 7. Weight losses of peat during drying (weight loss compared to the as-received sample) [24].

In FT-IR spectroscopy, water can be determined by the broad hydrogen bonding region (3500-3000 $\mathrm{cm}^{-1}$ ); this was used to investigate the water content differences between PEL20 and PEL55. The spectra of PEL20 and PEL55 are shown in Figure 8. The data confirm differences in moisture content between both samples. For each moisture content, three repeat tests were performed, and they showed little variation. Besides water, the spectra also indicate that peat consists of saturated organic groups, alcoholic groups, a very small amount of $\mathrm{C}=\mathrm{O}$ groups, and probably also inorganic material, indicated by the large signal at $1000 \mathrm{~cm}^{-1}$. Moreover, there were no differences in the spectra of the powder and the fiber fraction, indicating that both fractions are chemically identical. Similarities to the spectrum of cellulose were also observed, indicating that the findings for the peat material may be very similar to what is seen for cellulose fibers.

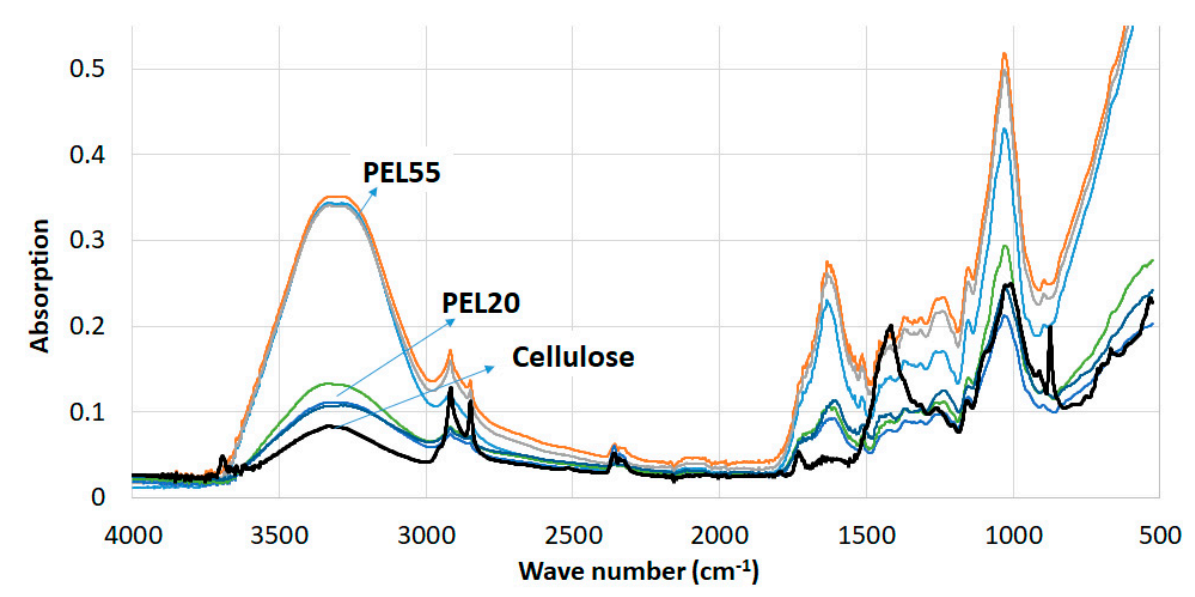

Figure 8. FT-IR spectra of medium peat fibers containing two water contents [24]. 
Peat bitumen blends were investigated by rheological test methods. In the initial tests, the peat bitumen samples were prepared in $100 \mathrm{~mL}$ cans, and from these cans, specimens for the rheological tests were taken. However, the repeatability of the so-obtained data was not very high, showing a difference of about $30 \%$ between tests on material from the same can, but different specimens. This was only the case for the fiber-modified samples. For the bitumen modified with powder, the repeatability was on the same level as for unmodified binders. Therefore, several actions were taken to improve the repeatability of the fiber-modified samples. Test samples were prepared directly in a silicon mold with the same dimensions as the specimen needed for the rheometer, in a sample size of $1 \mathrm{~g}$. In this way, it was assured that the added amounts were also present in the test sample. Additionally, the fibers were cut to about $5 \mathrm{~mm}$ in length.

In rheological tests, it is common practice to test inside the linear viscoelastic (LVE) range of the material. Within this region, weak structures and networks will stay intact and particles, if present in the sample, will not be deformed. As an example, stress sweeps at $50{ }^{\circ} \mathrm{C}$ and $0.1 \mathrm{~Hz}$ are plotted in Figure 9. The evolution of the complex modulus and the phase angle with strain are shown for various bitumen (base binder is denoted as REF), fiber and powder combinations. As these tests were conducted on heterogeneous materials, the samples were observed very carefully to assure that the sample radius and shape were still intact after each test. The obtained data indicate a nice LVE range for the unmodified and the powder-modified binders. However, the fiber-modified binders are extremely strain-sensitive even at low strain levels, and the modulus and elasticity decrease quickly with increasing strain, indicating damage or rearrangements in the sample structure.

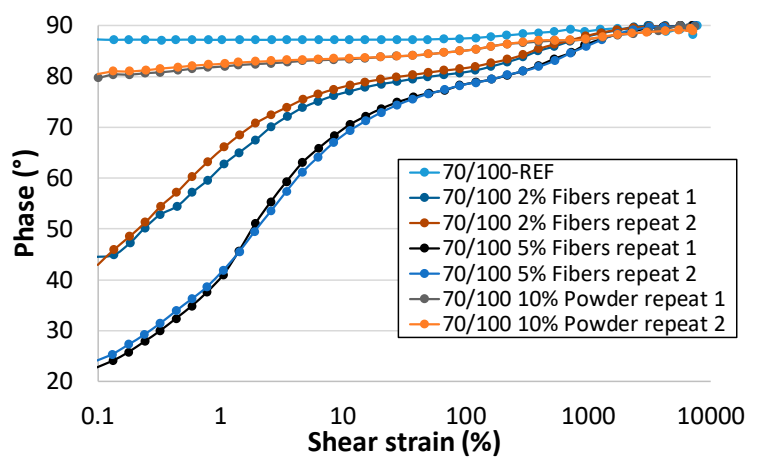

(a)

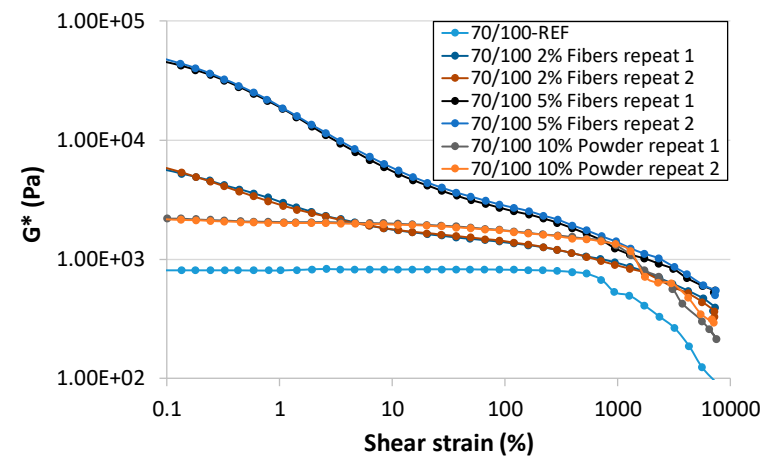

(b)

Figure 9. Stress sweeps taken at $50{ }^{\circ} \mathrm{C}$ and $0.1 \mathrm{~Hz}$ : (a) complex modulus and (b) phase angle.

For one sample, the effect of what happens after a high strain was investigated further. In this test, the changes after applying a strain sweep were followed with time by applying an oscillation at low strain $(0.1 \%)$. The strain sweeps as well as the "recovery" period at low strain are shown in Figure 10a,b. It is obvious that, after the strain sweep, which in this case went up to $200 \%$, the fiber-modified sample can recover the modulus and phase angle almost back to its starting value. In these tests, the sample was visually checked and remained unchanged, so edge effects can be excluded.

Frequency sweeps at $50^{\circ} \mathrm{C}$ were also performed using a strain of $1 \%$ for all the samples. The results are shown in Figure 11a,b. When adding powder to bitumen, there is mainly a stiffening effect. However, when adding fibers, there is an effect on the elasticity, especially at low frequencies. All measurements were made in duplicate, resulting in very similar results.

The formation of a plateau modulus at low frequencies in the fiber-modified samples was further investigated. For the reference binder and the $2 \%$ fiber-modified sample, the frequency sweep at $50{ }^{\circ} \mathrm{C}$ was extended, based on horizontal shift factors, by frequency sweeps at $40^{\circ} \mathrm{C}, 60^{\circ} \mathrm{C}$, and $70{ }^{\circ} \mathrm{C}$. This is shown in Figure 12. These data show that the storage and loss modulus are moving to a plateau modulus if the frequency decreases or the temperature increases, in the investigated temperature range. 


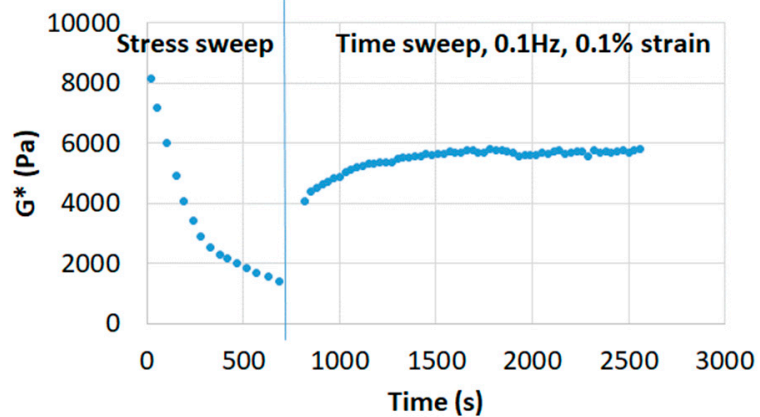

(a)

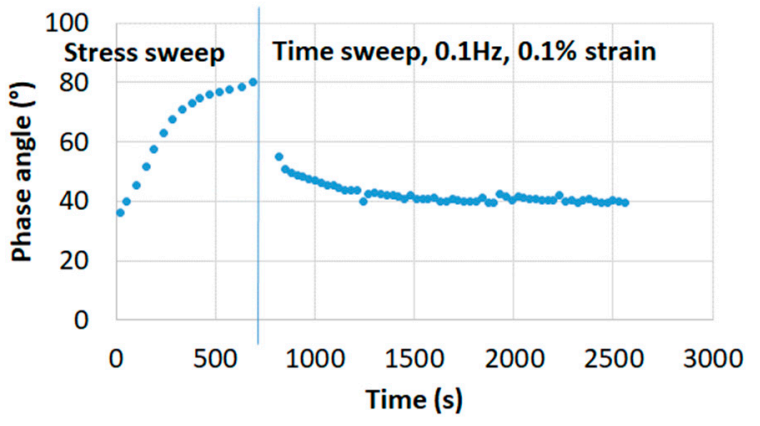

(b)

Figure 10. The recovery after stress sweeps on a $2 \%$ fiber sample $\left(50^{\circ} \mathrm{C}, 0.1 \mathrm{~Hz}\right)$ : (a) complex modulus and (b) phase angle.

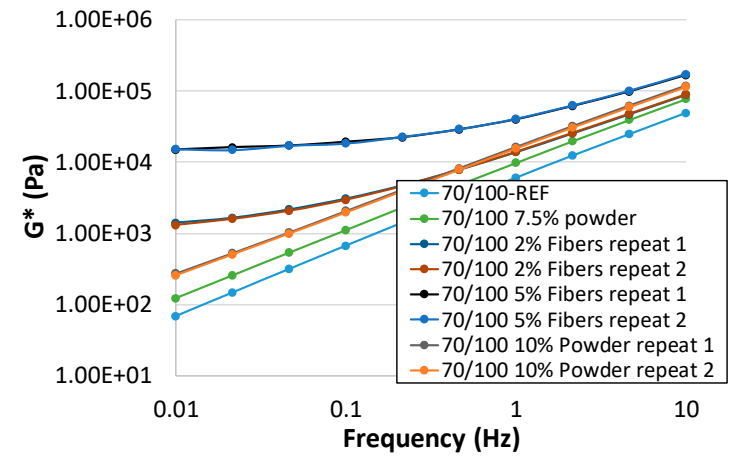

(a)

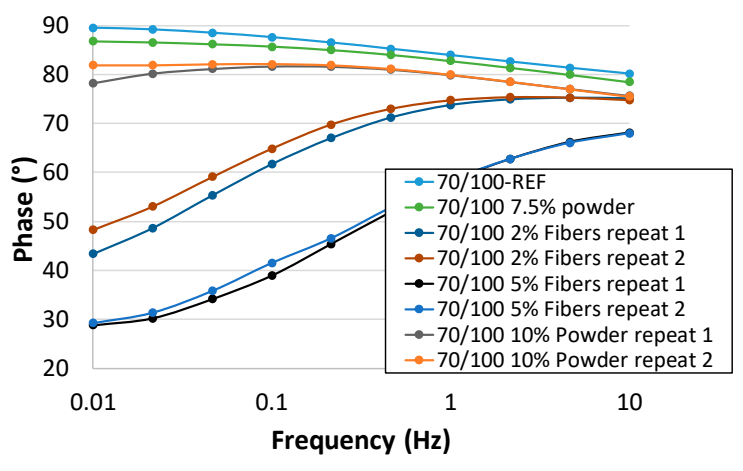

(b)

Figure 11. Frequency sweeps at $50{ }^{\circ} \mathrm{C}, 1 \%$ strain: (a) complex modulus and (b) phase angle.

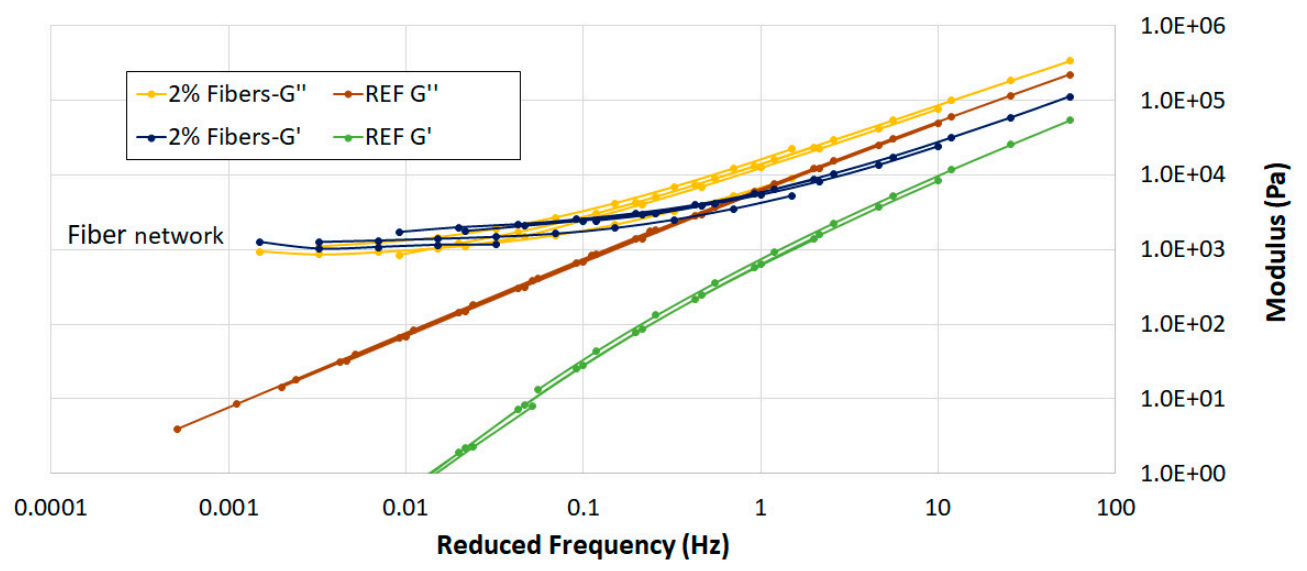

Figure 12. The master curves at $50{ }^{\circ} \mathrm{C}$ for the reference binder and the $2 \%$ fiber sample.

Finally, repeated creep tests were performed at $50{ }^{\circ} \mathrm{C}$, according to the multiple stress creep and recovery test (MSCRT) specification [25]. This test is developed as a performance-based binder test to predict asphalt rutting. The test results are plotted in Figure 13, while the calculated parameters are shown in Table 1. These data indicate that, as the modification level with fibers increases, the rutting resistance could improve. Even adding a small percentage of fibers ( $0.1 \mathrm{wt} \%$ fibers, see Figure 13$)$, already has an effect. As the fiber percentages increase, the percentage recovery increases and the non-recoverable compliance, as well as the end strain level, decreases. In the MSCRT tests, the recovery part and the non-recoverable part are dependent on the stress level. This corresponds to the behavior observed in the stress sweeps. 


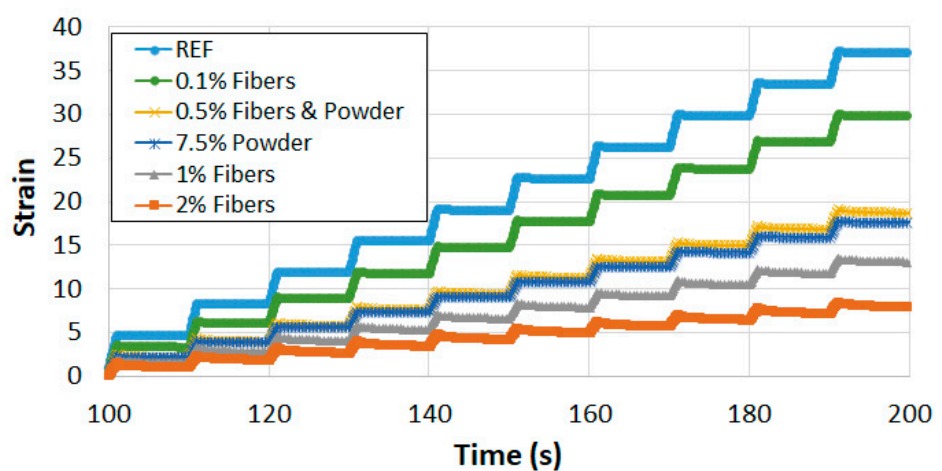

Figure 13. The multiple stress creep and recovery (MSCRT) test results, $50{ }^{\circ} \mathrm{C}$ (only repeated creep tests at $3200 \mathrm{~Pa}$ are shown).

Table 1. The parameters derived from the MSCRT test for various bitumen-peat combinations at $50{ }^{\circ} \mathrm{C}$.

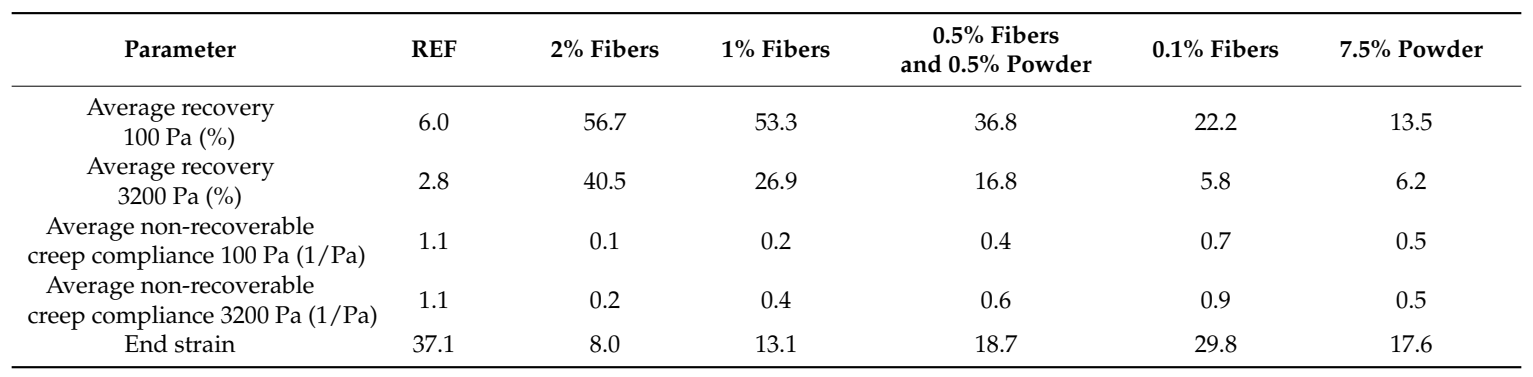

When interpreting the rheological data, it is important to consider that these samples consist of very different phases. The fibers, and the powder, are embedded in an almost unmodified bitumen phase, there are fiber-fiber contacts, and the fibers are long (long enough to bridge the gap between the plates). The effects of adding powder or fibers to a base binder are quite different: powders stiffen the binder, while the fibers also induce an elastic effect. In the fiber-added blends, the elastic effects are due to the fiber skeleton. This skeleton becomes obvious, under test conditions of frequency and temperature, where the binder stiffness is in the same range or below that of the skeleton. For example, for the blend modified with $2 \%$ fibers, the modulus level of the fiber network is around $1 \mathrm{kPa}$, and for $5 \%$ fibers it is around $10 \mathrm{kPa}$. In the frequency sweeps, there is a frequency range where the binder stiffness is in the same range as the one of the fiber network; at $50{ }^{\circ} \mathrm{C}$, this frequency is around $0.1 \mathrm{~Hz}$ for $2 \%$ fibers and $1 \mathrm{~Hz}$ for $5 \%$ fibers.

When tested at higher frequencies, the binder stiffness determines the behavior; if the frequency is reduced, the modulus of the binder drops below the one of the fiber network. In that case, the fiber network is determining the rheological test result, and, as this network is stiff, it is rather independent of frequency or loading time which results in an elasticity effect. As the network points formed by the fibers are just loose contact points, they can start to move under high strain, explaining the high strain dependency that was observed. Surprising is the recovery seen in the creep-recovery tests and after the stress sweep. This indicates that although the network points in the fiber skeleton are loose they still tend to move back to their initial position after deformation. This could be related to the stiff character of these fibers.

It is known that fibers are used to prevent drainage. The optimal amount of fibers (\%) per asphalt mix composition was defined in [14] to keep an asphalt batch mass homogeneous by manual mixing. A variation in fibers of $0.3-1.5 \%$ was applied, and, according to the obtained results, it was decided to keep $0.5 \%$ of peat fibers per mix. According to the drainage test results, the amount of drained material for the reference mix was $0.33 \%$ (see Figure $14 \mathrm{~b}$ ), and no drainage was observed for mixes modified with PEL20. The data show that peat fibers (ground/non-ground) are effective in reducing or even preventing drainage. 


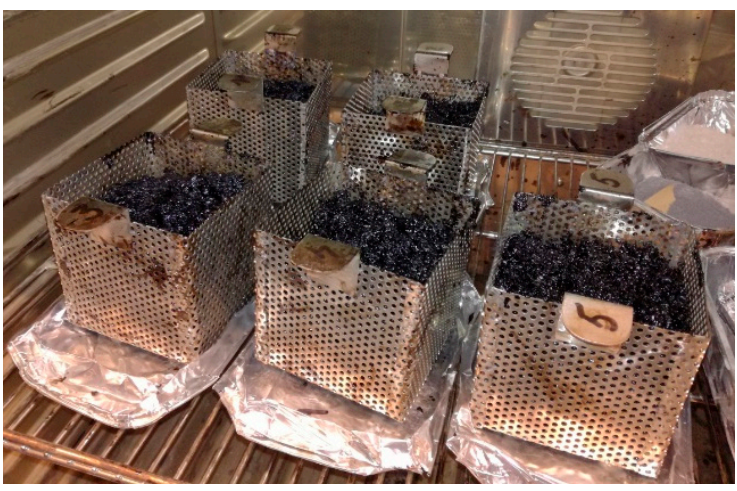

(a)

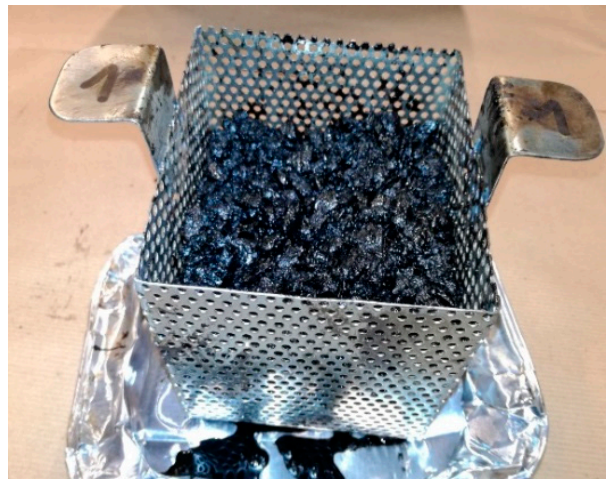

(b)

Figure 14. The drainage test: (a) asphalt mixes with peat and (b) the REF asphalt mix [24].

During the drainage test, it was observed that a direct addition of peat fibers into the asphalt mix, and mixing it manually, does not really result in a homogeneous spread of the fibers in the asphalt mix. To obtain a more homogeneous mixing, two approaches were compared: (1) a dry process: direct mixing of peat fibers with hot aggregates, before or after adding bitumen and filler in the mixer (see Figure 15a); and (2) a wet process: blending the peat fibers with a Janke \& Kunkel RW-20 variable-speed stirrer at speed of $300 \mathrm{rpm}$ in hot bitumen at the temperature of $150{ }^{\circ} \mathrm{C}$ with specially designed steel blades before adding it to the hot aggregates mix (see Figure 15b). To reach a homogeneous distribution of peat fibers in the asphalt mix, mixing should be performed only by the second approach; with the first approach, this homogeneity cannot be reached (see Figure 16). This is remarkable, since, considering the type and length of fibers, it has been reported in the literature that dry mixing was supposed to be sufficient $[4,9,15,26]$ or it was not mentioned at all how fibers were mixed in the asphalt mixes $[5-8,11,16]$.

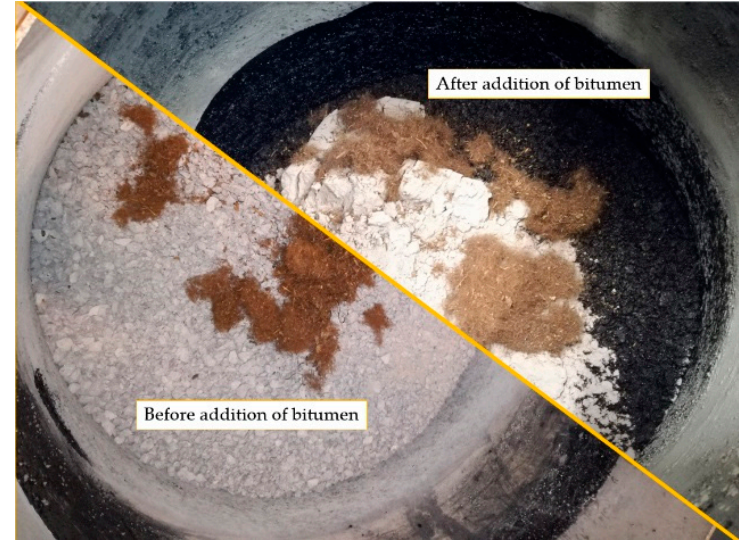

(a)

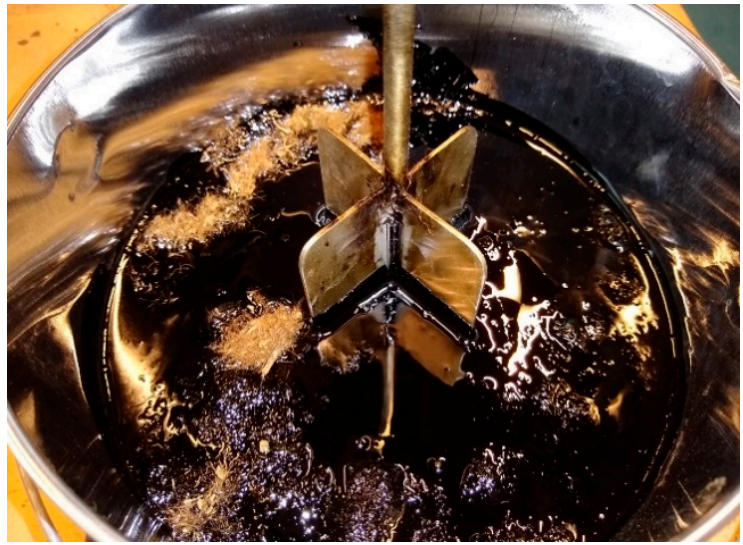

(b)

Figure 15. Mixing of peat fibers in the asphalt mix: (a) the first approach and (b) the second approach.

It was mentioned by Kumar et al. [15] that natural fibers tend to mix thoroughly with dry heated aggregates. During the present experimental study, it was observed that natural fibers might tend to mix thoroughly with dry heated aggregates, depending on the length of the fibers (no more than $10 \mathrm{~mm}$ in length); however, as soon as the binder is added into the mix, the homogeneous fiber distribution disappears, which can be clearly observed in Figure 16 on the slab surface. Button and Lytton already in 1987 stated that the proper quantity of bitumen for a consistent coating of all particles is different not only for different concentrations but also for different types of fibers. This is likely due to the variations in surface area of the different fiber types. In addition, mix design procedures showed that 
the incorporation of fibers in an asphalt mix will increase the resulting air void content when the compaction effort remains constant [17].

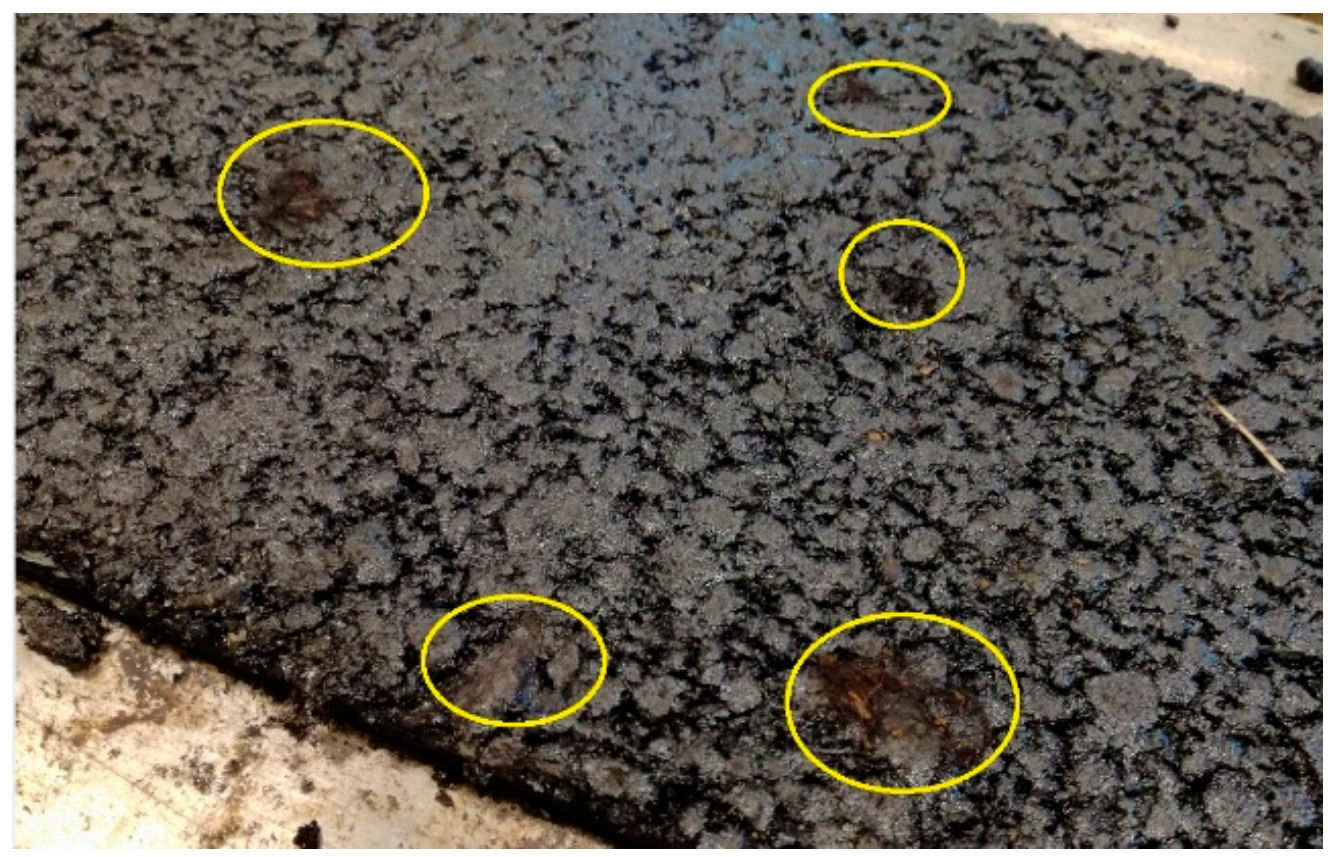

Figure 16. An example of an asphalt slab produced by the dry approach (mixing peat with aggregates in the asphalt mix).

In this study, several slabs were produced: (1) two reference slabs (denoted as REF), (2) two slabs with $0.5 \%$ peat fibers and $0.5 \%$ peat powder (FPEL20), and (3) two slabs with $1 \%$ peat fibers in the asphalt mix. In these tests, the mix design was not changed since the fiber and powder percentages were small. The rut depth results are shown in Figure 17. It can be seen that there is no significant difference among the results. The addition of peat fibers seems to reduce the rut depth, as was predicted from rheological tests, but the effect is in fact too small to be considered.

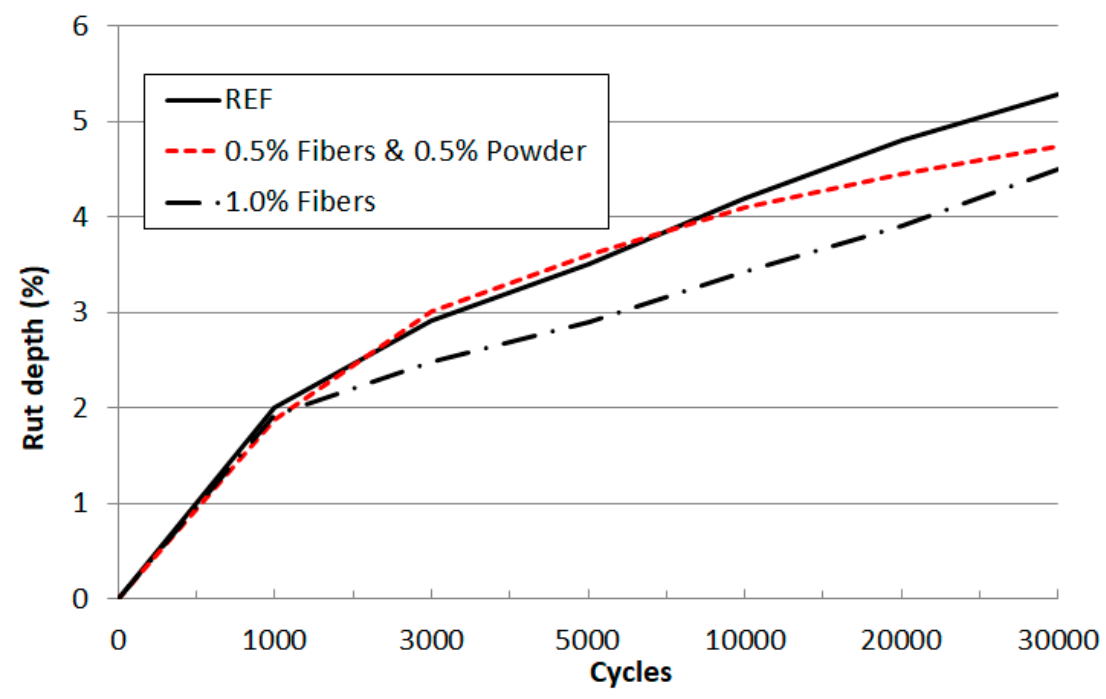

Figure 17. Examples of wheel tracking tests $\left(50^{\circ} \mathrm{C}\right)$.

Finally, the air voids (AV) for the various slabs was determined. The results are shown in Table 2. It is very clear that adding peat fibers or peat powder or very fine peat powder leads to a larger void 
content and shows that compaction becomes more difficult. When adding this material to asphalt, the mix design needs to be re-optimized.

Table 2. Air void properties of the slabs.

\begin{tabular}{cc}
\hline Mix & AV, \% \\
\hline REF & 5.15 \\
$0.5 \%$ Fibers and 0.5\% Powder & 6.53 \\
1.0\% Fibers & 8.80 \\
\hline
\end{tabular}

\section{Conclusions}

In this study, the applicability of a natural peat fiber, as a modifier for bitumen, was investigated. It was noticed that the peat fiber material did not dissolve in bitumen, not even partly. Only for the very fine powder fraction some color change was observed in toluene and in acetone. Therefore, the peat products, whether this is the powder or the fiber, cannot be regarded as a bitumen extender or modifier; they should be treated as solid additives.

Rheological tests were carried out, and despite the heterogenous nature of the investigated blends of bitumen, powder, and fiber, the tests showed repeatable and consistent results, indicating some trends: the powder part mainly acts as a filler and the fiber part introduces an increment of elasticity. The data also show that the elastic action of the fibers is weak and quickly destroyed at higher stresses. As both the fiber part and the powder part show similar FT-IR spectra, the differences in the rheological behavior are related to the size difference of these components. A fiber skeleton is observed in the rheological tests when the binder has a stiffness that is similar or lower as compared to this network. Under test conditions where the binder is stiffer, a binder phase is observed, while, as soon as the binder stiffness drops or is in the same range as the fiber network, this network will influence and determine the rheological behavior. MSCRT tests were also conducted and indicated recovery effects, again mainly when adding fibers. This would suggest that especially the fibers could improve the rutting resistance; however, it was not possible to confirm this in asphalt rutting tests.

The asphalt drainage tests have shown that adding dry peat, whether this is ground or not, is effective in reducing the binder drainage, and, consequently, from this point of view would allow for thicker binder films around the aggregate. However, if the mix design is not adapted, the amount of added peat fibers and powder should be limited to keep the mixes workable. Compaction problems became obvious and resulted in high void contents.

When mixing peat fibers and powder with asphalt, it was observed that, to reach a homogeneous distribution of peat fibers in the asphalt mix, mixing should be performed only by the wet method; i.e., by blending the peat fibers in hot bitumen before adding them to the hot aggregates in the mixer. Direct mixing of peat fibers with hot aggregates and filler before adding the bitumen does not guarantee an even distribution of the fibers in the asphalt mix.

As a continuation, it could be worthwhile to investigate how powder and fibers influence the asphalt performance, when a thicker binder film is used, and when the mix design is re-optimized. In this way, modified asphalt mixes with sufficient workability and compactability could be compared. Also, possible beneficial effects of using peat fibers on the cracking resistance and investigation of the distribution of peat fibers in the asphalt mix with X-ray computed tomography (X-ray CT), which have not been investigated in this study, could be interesting to provide more information.

Author Contributions: Conceptualization, P.K.D.M. and H.S.; Data curation, H.S. and P.K.D.M.; Investigation, H.S., P.K.D.M., J.S., and G.J.; Resources, H.S. and W.V.d.b.; Writing-original draft preparation and editing, P.K.D.M. and H.S.; Writing-review, W.V.d.b. and J.B.

Funding: This research was funded by NYNAS.

Acknowledgments: The authors would like to thank VAPO (https:/ /www.vapo.com/en) for providing peat material; the UAntwerp Mechanics Workshop for preparing perforated steel boxes for the drainage test, the rut 
depth measuring setup for rutting test, and steel blades for the blending of bitumen with peat; and Ankersmid M\&C Bvba (www.ankersmid.eu) for providing the SEM.

Conflicts of Interest: The authors declare no conflict of interest.

\section{References}

1. VAPO. Peat Production; VAPO: Jyväskylä, Finland, 2016.

2. Energy in Finland. Communication and Information Services Statistics Finland. 2016. Available online: http:/ / www.stat.fi (accessed on 1 November 2018).

3. U. S. Geological Survey. Mineral Commodity Summaries. 2017. Available online: https://minerals.usgs. gov/minerals / pubs/mcs/2017/mcs2017.pdf (accessed on 1 November 2018).

4. Mahrez, A.; Karim, M.R.; Katman, H.Y. Fatigue and deformation properties of glass fiber reinforced bituminous mixes. J. East Asia Soc. Trans. Stud. 2005, 6, 997-1007. [CrossRef]

5. Bindu, C.S.; Beena, K.S. Influence of additives on the drain down characteristics of stone matrix asphalt mixtures. Int. J. Res. Eng. Technol. 2014, 3, 83-88.

6. Sheng, Y.; Zhang, B.; Yan, Y.; Li, H.; Chen, Z.; Chen, H. Laboratory investigation on the use of bamboo fiber in asphalt mixtures for enhanced performance. Arab J. Sci. Eng. 2018, 1-10. [CrossRef]

7. Tamburini, C.; Ziyani, L.; Dony, A.; Rohart, C.; Toraldo, E. Promotion of bitumen-impregnated cellulose fibers from lightweight roofing tiles in stone mastic asphalt. In RILEM 252-CMB: RILEM 252-CMB-Symposium on Chemo-Mechanical Characterization of Bituminous Materials; Poulikakos, L.D., Falchetto, A.C., Wistuba, M.P., Hofko, B., Porot, L., di Benedetto, H., Eds.; Springer: Cham, Switzerland, 2019; Volume 20, pp. 306-3011. ISBN 978-3-030-00475-0. [CrossRef]

8. Awanti, S.S.; Habbal, A.; Hiremath, P.N.; Tadibidi, S.; Hallale, S.N. Characterization of stone matrix asphalt with cellulose and coconut fiber. In Advance in Civil Engineering and Building Materials; Chang, S., al Bahar, S.K., Zhao, J., Eds.; Taylor \& Francis Group: London, UK, 2012; pp. 639-642. ISBN 9780203388075.

9. Ting, T.L.; Jaya, R.P.; Hassan, N.A.; Yaacob, H.; Jayanti, D.S. A review of utilization of coconut shell and coconut fiber in road construction. Jurnal Teknologi (Sci. Eng.), 2015, 76, 121-125. [CrossRef]

10. Delgado, H.; Arnaud, L. Investigation of the fatigue properties of asphalt mixtures reinforced with natural fibers. In Proceedings of the International Conference Bituminous Mixtures and Pavements, Thessaloniki, Greece, 1-3 June 2011; ISBN 978-9-609-992206.

11. Kumar, P.; Sikdar, P.K.; Bose, S.; Chandra, S. Use of jute fiber in stone matrix asphalt. Road Mater. Pavement 2004, 5, 239-249. [CrossRef]

12. Dong, T.; Xu, G.; Wang, F. Adsorption and adhesiveness of kapok fiber to different oils. J. Hazard. Mater. 2015, 296, 101-111. [CrossRef]

13. Kudrjashov, A.P.; Kudrjashov, I.V.; Kudrjashov, P.A.; Germashev, V.G.; Jadykina, V.V. Stabilising Additive for Peat-Based Asphalt-Concrete Mixture (Versions) and Method of Producing Structure-Forming Agent Thereof. Patent RU 2479524 C2, 20 April 2013.

14. Soenen, H.; Kara De Maeijer, P.; Blom, J.; Van den bergh, W. Peat as an example of a natural fiber in bitumen. In RILEM 252-CMB: RILEM 252-CMB-Symposium on Chemo-Mechanical Characterization of Bituminous Materials; Poulikakos, L.D., Falchetto, A.C., Wistuba, M.P., Hofko, B., Porot, L., di Benedetto, H., Eds.; Springer: Cham, Switzerland, 2019; Volume 20, pp. 300-305, (first online on 13 September 2018); ISBN 978-3-030-00475-0. [CrossRef]

15. Kumar, N.R.; Sunitha, V. Experimental investigation of stone mastic asphalt with sisal fiber. Int. J. Eng. Res. Technol. (IJERT) 2016, 5, 546-550.

16. Oda, S.; Fernandes, J.L.; Ildefonso, J.S. Analysis of use of natural fibers and asphalt rubber binder in discontinuous asphalt mixtures. Constr. Build. Mater. 2012, 26, 13-20. [CrossRef]

17. Button, J.W.; Lytton, R.L. Evaluation of Fabrics, Fibers and Grids in Overlays. In Proceedings of the Sixth International Conference on the Structural Design of Asphalt Pavements, Ann Arbor, MI, USA, 13-17 July 1987; pp. 925-934. Available online: https://static.tti.tamu.edu/tti.tamu.edu/documents/TTI-1987-ID19631.pdf (accessed on 2 November 2018).

18. Perdana, L.R.; Ratnasari, N.G.; Ramadhan, M.L.; Palamba, P.; Nasruddin, N.; Nugroho, Y.S. Hydrophilic and hydrophobic characteristics of dry peat. IOP Conf. Ser. Earth Environ. Sci. 2018, 105, 012083. [CrossRef]

19. NBN EN 15326+A1 Bitumen and Bituminous Binders-Measurements of Density and Specific Gravity-Capillary-Stoppered Pycnometer Method; Bureau for Standardisation: Brussels, Belgium, 2009. 
20. NBN EN 12697-18, Bituminous Mixtures_Test Methods for Hot Mix Asphalt_Part 18: Binder Drainage; Bureau for Standardisation: Brussels, Belgium, 2017.

21. NBN EN 12697-22, Bituminous Mixtures_-Test Methods for Hot Mix Asphalt_Part 22: Wheel Tracking; Bureau for Standardisation: Brussels, Belgium, 2007.

22. NBN EN 12697-5, Bituminous Mixtures_Test Methods for Hot Mix Asphalt_Part 5: Determination of the Maximum Density; Bureau for Standardisation: Brussels, Belgium, 2010.

23. NBN EN 12697-6, Bituminous Mixtures_Test Methods for Hot Mix Asphalt_Part 5: Determination of the Bulk Density of Bituminous Specimens; Bureau for Standardisation: Brussels, Belgium, 2012.

24. Soenen, H.; Kara De Maeijer, P.; Blom, J.; Van den bergh, W. Peat as an example of a natural fiber in bitumen. Presented at RILEM 252-CMB: RILEM 252-CMB-Symposium, Braunschweig, Germany, 17 September 2018; Available online: https:/ / www.researchgate.net/publication/325949164_Peat_as_an_Example_of_a_Natural_Fiber_ in_Bitumen_Chemo-Mechanical_Characterization_of_Bituminous_Materials (accessed on 1 November 2018).

25. CEN EN 16659, Bitumen and Bituminous Binders-Multiple Stress Creep and Recovery Test (MSCRT); Bureau for Standardisation: Brussels, Belgium, 2016.

26. Abiola, O.S.; Kupolati, W.K.; Sadiku, E.R.; Ndambuki, J.M. Utilisation of natural fiber as modifier in bituminous mixes: A review. Constr. Build. Mater. 2014, 54, 305-312. [CrossRef]

(C) 2019 by the authors. Licensee MDPI, Basel, Switzerland. This article is an open access article distributed under the terms and conditions of the Creative Commons Attribution (CC BY) license (http://creativecommons.org/licenses/by/4.0/). 